\title{
MATCHING PRODUCTION PLANNING AND SHIP ARRIVAL SCHEDULING BY SIMULATION
}

\author{
Marcelo Moretti Fioroni \\ Luiz Augusto G. Franzese \\ Caio Eduardo Zanin \\ José Alexandre Sereno Quintáns \\ Lúcia Dini Pereira \\ Isac Reis de Santana \\ Paulo Savastano \\ Paragon Tecnologia \\ Rua Clodomiro Amazonas, $1435,5^{\text {th }}$ floor \\ 04537-012 São Paulo, Brazil
}

\author{
Sydney Santos Cordeiro \\ Luiz Francisco da Silva \\ Vítor Luciano de Almeida Benevides
}

\author{
Anglo Ferrous Brazil \\ Av Inf Henrique, 345 - Aterro do Flamengo \\ 20021-140 Rio de Janeiro, Brazil
}

\begin{abstract}
There are several challenges involving the representation of an ore loading port system using a simulation package. This kind of port handles bulk material, much more adequately represented by continuous flow than discrete flow, as in opposite to the case of a container-handling port. This paper addresses specifically the impact of meeting product mix requirements in the delivery and the ship arrival schedules. A method to model this feature is presented. Also, the modeling approach of these aspects is presented, and the experimentation in the case of Porto do Açu, located at Rio de Janeiro, is performed to check the method's efficiency.
\end{abstract}

\section{INTRODUCTION}

Some of the most favorable applications of simulation studies, are the port projects. Ports involve expensive equipment, large scale cargo movement and heavy fines for delays. Also, the efficient use of ports is critical to countries, since they usually are the most important structure demanded to drain the export production.

This kind of simulation study is even more important if the port is still being designed. The simulation of the chosen design can help to find problems or improve its performance. It can save millions only by avoiding some design or operation mistakes, that would be much more difficult to fix in an operating port.

Countries that are great commodities producers and exporters have ports specially designed to load bulk products like grains or coal into ships that are also specially designed to carry these type of products.

An ore loading port system has special features not usually found on other kinds of ports:

- The product to be loaded is bulk material. Thus, a very specific system is needed to move the material from one place to another. Usually, it is done by conveyor belts.

- The bulk material must be stored in piles. These piles must be handled by equipment specially designed for this purpose: stackers, that store material and build the pile, and reclaimers, that remove material from it. 
- A specially designed equipment is necessary to load ships: the shiploader. It is fed by a conveyor belt that transports ore from the pile into one of the ship's compartments.

Also, bulk material ports present other usual problems that are common to regular ports:

- Ship arrivals must follow traffic rules involving weather, channel occupation and tide variations.

- There must be balance between product arrivals and ship arrivals, or the storage space might not be enough.

This particular problem demands special treatment when there is no real system to collect the data. It is important for the simulation user to have a way to "draw" the production planning pattern and the scheduling of ship arrival.

By doing this, the user can test the storage/loading system on many scenarios, determining the best equipment to be installed or the maximum capacity of the system. In fact, this approach can be used on any study of no-existing systems, where there is a production plan or transport arrival.

This technique was validated over a real case, which is presented below. Also, other important features are presented.

\section{THE PRODUCTION PLANNING VS. SHIP ARRIVAL PATTERN}

In many simulation studies, the system starts with a single, unlimited, "source" of jobs, and ends on an unrestricted sink point, like the one at Figure 1. This kind of simulation is commonly used to study the system performance, assuming that the jobs arrivals are known.

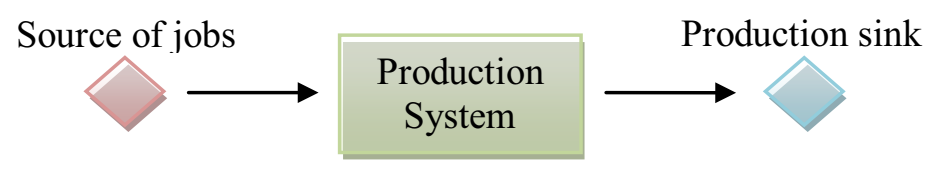

Figure 1: Simulation with a simple jobs arrival, ending on an unrestricted sink point

Also, it is very common to have studies with a more sophisticated source of jobs, that mimic a production plan, with more than one product type. Even these studies have an unrestricted production sink, because the main goal is to check how the production will perform under different production plans. This system is illustrated at Figure 2

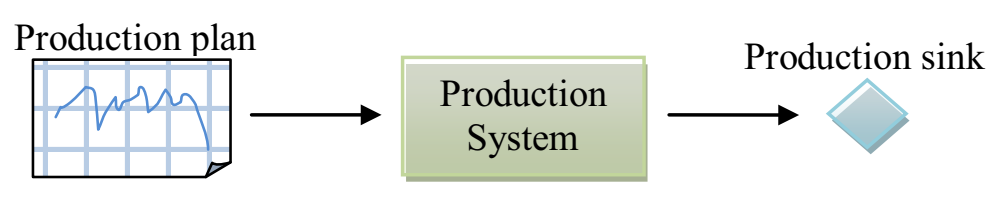

Figure 2: Simulating a production plan

In some rare cases, like this one, the production sink is not unrestricted. The output is determined by another arrival: the schedule of transportation equipment, like the one presented on Figure 3. In this case, it is mandatory to match the production planning with the transportation arrival. 


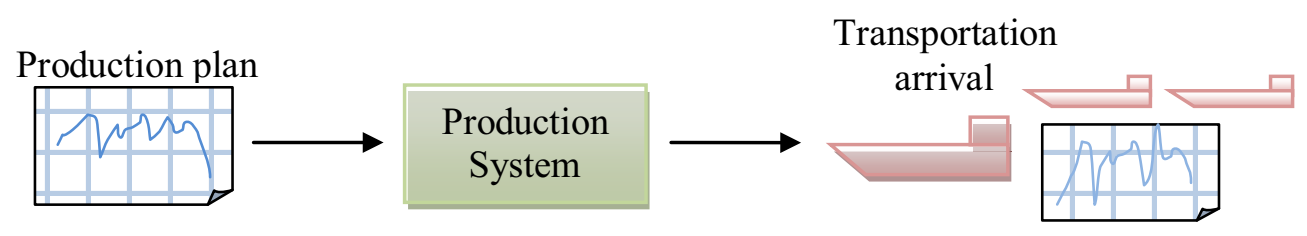

Figure 3: Simulating a production plan with restricted output

When it occurs in a port simulation study, the system has an additional problem: delayed ships incur fine. So, different than a truck or rail car arrival, the ship arrival does affect the monetary results, and cannot be ignored. This means that if the production plan provides a product $\mathrm{A}$, but there are only ships waiting for product $\mathrm{B}$, someone will be in trouble.

On a real, existing system, all these follow sales information. The sales area generates the production plan for product $\mathrm{A}$ or $\mathrm{B}$, and, knowing the production system times and behavior, the dispatcher creates the ship arrival schedule.

On a simulated, non-existing system, this must be generated in a different way, because the "production system times and behavior" are not known: they vary on every scenario when testing new equipment or production strategy. And the Sales department do not exist too, so there is no precise information to support a detailed production plan.

The next section proposes a method to provide both plans for a simulation model of such system.

\section{PLAN INPUT}

\subsection{Production Plan}

The representation of the production plan is not a challenge, since there is an assumption that it will be presented to the production system as-is. Assuming the system works on one task a time, the production plan is just a list of the products to be produced, and its quantity.

The following example, presented on Figure 4, comes from an iron ore beneficiation plant, which has 4 product types.

\begin{tabular}{|c|c|c|c|c|c|c|c|c|c|c|c|}
\hline \multicolumn{3}{|c|}{ Sequence 1 to 25} & \multicolumn{3}{|c|}{ Sequence 26 to 50} & \multicolumn{3}{|c|}{ Sequence 51 to 75} & \multicolumn{3}{|c|}{ Sequence 76 to 100} \\
\hline Sequence & Product & Ton & Sequence & Product & Ton & Sequence & Product & Ton & Sequence & Product & Ton \\
\hline 1 & 1 & 300,000 & 26 & 4 & 100.000 & 51 & 2 & 300,000 & 76 & 4 & 100,000 \\
\hline 2 & 1 & 100.000 & 27 & 1 & 300.000 & 52 & 3 & 100.000 & 77 & 3 & 300,000 \\
\hline 3 & 3 & 300,000 & 28 & 4 & 200,000 & 53 & 2 & 300,000 & 78 & 4 & 200,000 \\
\hline 4 & 1 & 100.000 & 29 & 1 & 430.000 & 54 & 3 & 100.000 & 79 & 3 & 430.000 \\
\hline 5 & 2 & 300,000 & 30 & 4 & 200.000 & 55 & 2 & 300,000 & 80 & 4 & 200,000 \\
\hline 6 & 1 & 100,000 & 31 & 1 & 430,000 & 56 & 3 & 100,000 & 81 & 3 & 430,000 \\
\hline 7 & 2 & 300,000 & 32 & 4 & 200,000 & 57 & 2 & 300,000 & 82 & 4 & 200,000 \\
\hline 8 & 1 & 100,000 & 33 & 1 & 430,000 & 58 & 3 & 100,000 & 83 & 3 & 430,000 \\
\hline 9 & 2 & 300,000 & 34 & 4 & 89.000 & 59 & 2 & 300,000 & 84 & 4 & 123.000 \\
\hline 10 & 1 & 94,000 & 35 & 1 & 430.000 & 60 & 3 & 94.000 & 85 & 3 & 430,000 \\
\hline 11 & 2 & 300,000 & 36 & 4 & 89,000 & 61 & 2 & 300,000 & 86 & 4 & 89,000 \\
\hline 12 & 1 & 94,000 & 37 & 1 & 430,000 & 62 & 3 & 94,000 & 87 & 3 & 430,000 \\
\hline 13 & 2 & 300,000 & 38 & 4 & 89.000 & 63 & 2 & 300,000 & 88 & 4 & 89.000 \\
\hline 14 & 1 & 94.000 & 39 & 1 & 390.000 & 64 & 3 & 94.000 & 89 & 3 & 390.000 \\
\hline 15 & 2 & 400,000 & 40 & 4 & 89.000 & 65 & 2 & 400,000 & 90 & 4 & 34,000 \\
\hline 16 & 1 & 94.000 & 41 & 1 & 390.000 & 66 & 3 & 94.000 & 91 & 3 & 390.000 \\
\hline 17 & 2 & 400,000 & 42 & 4 & 89.000 & 67 & 2 & 400,000 & 92 & 4 & 89.000 \\
\hline 18 & 1 & 120.000 & 43 & 1 & 390,000 & 68 & 3 & 120,000 & 93 & 3 & 390,000 \\
\hline 19 & 2 & 400.000 & 44 & 4 & 89.000 & 69 & 2 & 320,000 & 94 & 4 & 490,000 \\
\hline 20 & 1 & 120,000 & 45 & 1 & 390,000 & 70 & 3 & 120,000 & 95 & 3 & 390,000 \\
\hline 21 & 2 & 400.000 & 46 & 4 & 89.000 & 71 & 2 & 400,000 & 96 & 4 & 89.000 \\
\hline 22 & 1 & 120.000 & 47 & 1 & 204,000 & 72 & 3 & 120,000 & 97 & 3 & 204,000 \\
\hline 23 & 2 & 400,000 & 48 & 4 & 89,000 & 73 & 2 & 400,000 & 98 & 4 & 89,000 \\
\hline 24 & 1 & 120,000 & 49 & 1 & 204,000 & 74 & 3 & 222,000 & 99 & 3 & 204,000 \\
\hline 25 & 2 & 400,000 & 50 & 4 & 89.000 & 75 & 2 & 400,000 & 100 & 4 & 89.000 \\
\hline
\end{tabular}

Figure 4: Example of a Production Plan 
Once such a plan is available, the model will just follow the sequence, producing the specified product type on the requested quantity. The impact and procedures on changing from one product to another must be in the model.

\subsection{Ship Arrival Generation}

To model the ship arrival is a greater challenge than modeling the production plan, because the ship arrival is subject to many interferences outside the scope of the model, like other ports delays, breakdowns, bureaucratic problems, weather on the way, etc. Also, other studies like the one from Asperen et al. (2003) have proven that a simple exponential interarrival time is the worst choice to represent it.

Every system that relies on cargo ships to dispatch products, has a storage system to keep the product waiting for the ship in advance. The idea is to always have the product ready to avoid ship delays and fines payment. Of course this storage space and its use must be carefully designed. The fact is that there is not a precise control, or a safe forecast on the ship arrival.

Assuming there is not an operational simulation, where every specific ship must be modeled and considered, the ship arrival generation can be represented as seen on Figure 5.

\begin{tabular}{|c|c|c|c|c|c|c|}
\hline & Ship types: & Type 1 & Type 2 & Type 3 & Type 4 & TOTAL \\
\hline Historic percentage & $\%$ & $10 \%$ & $20 \%$ & $70 \%$ & $0 \%$ & $100 \%$ \\
\hline Ship size: MINIMUM & KTons & 30 & 51 & 131 & 151 & \\
\hline Ship size: MOST COMMON & K Tons & 40 & 91 & 140 & 201 & \\
\hline Ship size: MAXIMUM & K Tons & 50 & 130 & 150 & 220 & \\
\hline \# of ships & \#/ year & 22 & 44 & 155 & 0 & 222 \\
\hline Volume to transport & K Tons & 888 & 4,018 & 21,756 & 0 & $26,662,200$ \\
\hline
\end{tabular}

Figure 5: Example of a Ship Arrival Generation

The proposed arrival plan is based on general information about the ships, that is available to the simulation user like:

- Percentage of each type of ship (different types mean different sizes),

- Minimum, most common, and maximum size of each type of ship,

- Total product volume to be dispatched

To create the arrival pattern, the user must first fill in the ship size information for each type. Then, is necessary to choose (based on historic data from other ports, or an strategic plan) the percentage of each type of ship. These percentages must sum to $100 \%$ and total volume to transport must match the total production plan presented in earlier section.

Smaller ships means faster operations, lower delay fines, but much more maneuver and mooring operations. They are also easier to find. Bigger ships are the opposite, with less mooring maneuvers but bigger delay fees (if happen). So the user can describe the exact pattern desired for the ship arrival.

Inside the model, the time between arrivals will use an exponential distribution, whose mean is calculated as follows:

$$
\text { mean }=\left(\frac{\text { simulation time }}{\text { total number of ships }}\right)
$$

Each arriving ship will have its type determined by an discrete distribution based on the percentages defined in the "historic percentage" row in Figure 5.

Once the type has been determined, the ship size will be given by a triangular distribution using the minimum, most common and maximum values as its parameters. 


\section{REAL CASE APPLICATION}

\subsection{The case of Porto do Açu of AngloFerrous Brasil}

Anglo Ferrous is the iron division of the well known Anglo American mining company.

Porto do Açu is currently in design and construction phase, developed to receive very large ships and to handle several different types of cargo, including containers and also ore from the Anglo Ferrous mines in the state of Minas Gerais.

First of all, the simulation of an ore handling port is very different from other kinds of ports, at which discrete cargo like containers are received, stored and loaded. This class of problem has been extensively studied, and some reference work is that of Meisel \& Bierwirth (2009) and Karlaftis, Kepaptsoglou, \& Sambracos (2009). The solutions and algorithms proposed in these studies do not apply to a continuous cargo flow port. This being the case, new developments were required to achieve a correct process representation.

The focus of the simulation developed for the case of Anglo was:

- Validating the projected conditions for the equipments and operational rules of the port, and verifying if the volume loaded is in accordance with what is being budgeted. The operational times of ships are also subject to validation.

- Verifying the impact on the overall indicators of operating two different products and not only one.

- Verifying the possibility of, in a longer future, increasing the port's capacity only by installing a larger shiploader equipment.

- Verifying the impact on the overall indicators of operating larger ships vs. smaller ones.

\subsection{The Model}

The major challenges that have emerged from the simulation of Porto do Açu are all results of the need to represent operational rules and details that have a significant impact on the overall indicators that are the main object of the simulation.

The navigation restrictions have a direct impact on the time that each ship spends in each phase of the process in the port. This has an impact not only over the total time spent by each ship in the system, but also over the occupation rates of resources such as berths and the total volume loaded annually at the port.

Furthermore, the correct representation of the movements of stackers, reclaimers and shiploaders across yards and ship compartments is essential for the correct assessment of the real hourly capacity of these equipments. Were the time spent on these movements very short, they would be irrelevant. However, these movements have consumed up to $15 \%$ of certain equipment's available time in some simulated scenarios, which has a clear impact on the annual loading capacity of the port, as well as in these equipment's utilization rates. Other ore yard studies, like Fioroni et al. (2007) and Coelho and Fioroni (2005), do not go further on that detail level.

Moreover, the need to test the port's indicators in situations where more than one product is being handled makes it inevitable for the simulation analyst to deal with the problem of meeting required product mix. While this aspect had not yet been effectively taken in hand, in the model validation phase, the simulation developed for Anglo Ferrous presented several scenarios of deadlock results due to the excess of one type of product and the lack of another. It is also important to note that although the stocking areas capacities were represented in the model, the goal was not to check if the stocking area had been correctly sized. If this was so, it might have been necessary to face the product mix challenge in a different way.

In short, it must be said that the approach chosen to represent the process at Porto do Açu allowed the correct assessment of the main indicators of the simulation. 


\subsection{Results}

The experimentation phase followed the process proposed by Valentin et al. (2005) to simulate maritime infrastructure, where a simulation expert builds the model and performs the experiments. Then, the results are analyzed by the port expert.

The results presented in Figure 6 show the production and the dispatch (ships loaded) for each scenario. It involves many other parameters that are not in the table. They were removed for confidentiality reasons.

Each scenario had a calibration phase to adjust the ship schedules to the desired production and system infrastructure, and this table shows that every scenario could successfully dispatch the production (input ships per year vs. output ships loaded).

Also, every scenario provided information about the storage space (courtyard level), that supported decisions involving the system.

\begin{tabular}{|c|c|c|c|c|c|c|c|}
\hline \multirow{6}{*}{ 与号 } & SCENARIOS & 1 & 2 & 3 & 4 & 5 & 6 \\
\hline & \multicolumn{7}{|c|}{ Loading System } \\
\hline & Number of different products & 2 & 2 & 2 & 2 & 2 & 2 \\
\hline & Ships per year & 135 & 194 & 135 & 323 & 135 & 167 \\
\hline & \multicolumn{7}{|c|}{ Production } \\
\hline & Production (Tons/Hr) & 1,700 & 2,465 & 1,700 & 4,080 & 1,700 & 2,104 \\
\hline \multirow{7}{*}{ 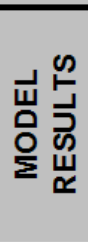 } & \multicolumn{7}{|c|}{ Loading System } \\
\hline & Ships loaded & 135 & 194 & 135 & 321 & 135 & 166 \\
\hline & Ave rage ship capacity (M tons) & 44.8 & 45.3 & 44.8 & 45.8 & 43.5 & 45.1 \\
\hline & Average ship time in system (h/ship) & 8.3 & 8.9 & 8.3 & 10.8 & 14.8 & 19.9 \\
\hline & Average que ue time per ship (h/ship) & 0.1 & 0.8 & 0.1 & 1.6 & 0.1 & 2.3 \\
\hline & \multicolumn{7}{|c|}{ Production } \\
\hline & Courtyard level (\%) & $44 \%$ & $44 \%$ & $44 \%$ & $38 \%$ & $38 \%$ & $38 \%$ \\
\hline
\end{tabular}

Figure 6: Results comparison.

\section{CONCLUSIONS}

The experimentation proved that the proposed method is efficient enough to support experimentation on simulation systems that have production planning variation and dispatch restrictions based on transportation arrival.

Despite the use of a port system as an example, the method can be used on every system with a production plan or arrival of transportation equipment.

In this specific case, it is mandatory to consider both the production plan and the ship arrival on the same model, because of some aspects of the system were the ship loading system that could impact directly on the storage system. On simpler systems, the process could be cut in half, with studies being performed with the system until the storage, and others from the storage to the ship loading system.

\section{ACKNOWLEDGMENTS}

The Authors thanks Anglo Ferrous for supporting this project and for authorizing the use of its information.

\section{REFERENCES}

Asperen, E., R. Dekker, M. Polman, S.H. Arons. 2003. Modeling Ship Arrivals in Ports. In Proceedings of the 2003 Winter Simulation Conference, ed. S. Chick, P. J. Sanchez, D. Ferrin, and D. J. Morrice, 1737-1744. Piscataway, New Jersey: Institute of Electrical and Electronics Engineers, Inc.

Coelho, R.J., and M.M. Fioroni. 2005. Estudo de expansão do sistema de manuseio de matérias-primas da CST através de simulação. In: 60 Annual ABM Congress. Belo Horizonte, MG, 25 - 28 jul., 2005. 
Fioroni, M. M., L.A.G. Franzese, J. Furia, L. de Toledo Perfetti, D. Leonardo, N. L. da Silva, and C.E. Zanin. 2007. Simulation of Continuous Behavior Using Discrete Tools: Ore Conveyor Transport. In Proceedings of the 2007 Winter Simulation Conference., ed. S.G. Henderson, B. Biller, M.-H. Hsieh,. J. Shortle, J.D.Tew, and R.R. Barton. 1655-1672. Piscataway, New Jersey: Institute of Electrical and Electronics Engineers, Inc.

Karlaftis, M. G., K. Kepaptsoglou, and E. Sambracos. 2009. Containership routing with time deadlines and simultaneous deliveries and pick-ups. Transportation Research Part E, 45:210-221.

Meisel, F., and C. Bierwirth. 2009. Heuristics for the integration of crane productivity in the berth allocation problem. Transportation Research Part E, 45:196-209.

Valentin, E. C., S. Steijaert, R.A. Bijlsma, and P. Silva. 2005. Approach for Modeling of Large Maritime Infrastructure Systems. In Proceedings of the 2005 Winter Simulation Conference., ed. M.E. Kuhl, N.M. Steiger, F.B. Armstrong, and J.A. Joines. 1577-1585. Piscataway, New Jersey: Institute of Electrical and Electronics Engineers, Inc.

\section{AUTHOR BIOGRAPHIES}

MARCELO MORETTI FIORONI is a simulation consultant with an Electrical Engineering degree, MSc. in Manufacturing and PhD in Logistics at University of São Paulo (USP). Has participated in almost 150 successful projects with simulation. Co-founder of PARAGON Tecnologia in 1992, the pioneer and leading consulting company in simulation in South America. Teaches Simulation at Faculdades Metropolitanas Unidas (FMU) in São Paulo, Brazil. Has trained more than 1,200 professionals in simulation. He can be contacted by email at<marcelo@paragon.com.br>.

CAIO EDUARDO ZANIN is a simulation consultant with an Electrical Engineering degree. Has participated in almost 10 successful projects with simulation and teaches simulation in Paragon. He can be contacted by email at<caio@paragon.com.br>.

LUIZ AUGUSTO G. FRANZESE is a simulation consultant with a Production Engineering degree and MSc. in Logistics, who has completed almost 150 successful projects with simulation. Founded PARAGON Tecnologia in 1992, the pioneer and leading consulting company in simulation in South America. Has trained more than 1,200 professionals in simulation. He can be contacted by email at $<$ augusto@paragon.com.br>.

LUCIA DINI PEREIRA is a simulation analyst with a Production Engineering degree from the University of São Paulo (USP) and a diploma for specialized Logistics studies from École Centrale de Lyon, in France. Her background is in decision-making analysis and mathematical modeling in several organizations in Brazil. She can be contacted at $<$ lucia@paragon.com.br>.

JOSÉ ALEXANDRE SERENO QUINTÁNS is a simulation consultant. He has participated in almost 10 successful projects with simulation and teaches simulation in Paragon. He can be contacted by email at <alexandre@paragon.com.br>.

ISAC REIS DE SANTANA is a simulation consultant. With Technical Degree, he has participated in almost 10 successful projects with simulation and teaches simulation in Paragon. He can be contacted by email at<isac@paragon.com.br>.

PAULO SAVASTANO is a simulation consultant. He has participated in almost 10 successful projects with simulation and teaches simulation in Paragon. $\mathrm{He}$ can be contacted by email at <paulo@paragon.com.br>. 
Fioroni, Franzese, Zanin, Quintáns, Pereira, Santana, Savastano, Cordeiro, Da Silva and Benevides

SIDNEY SANTOS CORDEIRO Works with simulation at Anglo Ferrous Brazil. He can be contacted by email at $<$ sidney.cordeirodlix.com.br $>$.

LUIZ FRANCISCO DA SILVA Works with simulation at Anglo Ferrous Brazil. He can be contacted by email at < luiz.francisco@1lx.com.br>

VITOR LUCIANO DE ALMEIDA BENEVIDES Coordinator for the project of implantation of Porto do Açu. Mechanical Engineer degree from Universidade Federal do Espírito Santo - UFES. Doing masters degree in Management at the Fundação Getulio Vargas - RJ. Specialist in Internationl Commerce and Logistics by the same university. He can be contacted by email at $<$ vitor.benevides@angloferrous.com.br>. 